IZA DP No. 4984

Ranking the Schools: How Quality Information Affects School Choice in the Netherlands

Pierre Koning

Karen van der Wiel

June 2010 


\title{
Ranking the Schools: How Quality Information Affects School Choice in the Netherlands
}

\author{
Pierre Koning \\ CPB Netherlands Bureau for Economic Policy Analysis \\ and IZA \\ Karen van der Wiel \\ CPB Netherlands Bureau for Economic Policy Analysis \\ and IZA
}

\section{Discussion Paper No. 4984 \\ June 2010}

\author{
IZA \\ P.O. Box 7240 \\ 53072 Bonn \\ Germany \\ Phone: +49-228-3894-0 \\ Fax: +49-228-3894-180 \\ E-mail: iza@iza.org
}

Any opinions expressed here are those of the author(s) and not those of IZA. Research published in this series may include views on policy, but the institute itself takes no institutional policy positions.

The Institute for the Study of Labor (IZA) in Bonn is a local and virtual international research center and a place of communication between science, politics and business. IZA is an independent nonprofit organization supported by Deutsche Post Foundation. The center is associated with the University of Bonn and offers a stimulating research environment through its international network, workshops and conferences, data service, project support, research visits and doctoral program. IZA engages in (i) original and internationally competitive research in all fields of labor economics, (ii) development of policy concepts, and (iii) dissemination of research results and concepts to the interested public.

IZA Discussion Papers often represent preliminary work and are circulated to encourage discussion. Citation of such a paper should account for its provisional character. A revised version may be available directly from the author. 


\section{ABSTRACT \\ Ranking the Schools: How Quality Information Affects School Choice in the Netherlands}

This paper analyzes whether information on high school quality published by a national newspaper affects school choice in the Netherlands. For this purpose, we use both school level and individual student level data. First, we study the causal effect of quality scores on the influx of new high school students using a longitudinal school dataset. We find that negative (positive) school quality scores decrease (increase) the number of students choosing a school after the year of publication. The positive effects are particularly large for the academic school track. An academic school track receiving the most positive score sees its inflow of students rise by 15 to 20 students. Second, we study individual school choice behaviour to address the relative importance of the quality scores, as well as potential differences in the quality response between socio-economic groups. Although the probability of attending a school is affected by its quality score, it is mainly driven by the travelling distance. Students are only willing to travel about 200 meters more in order to attend a wellperforming rather than an average school. In contrast to equity concerns that are often raised, we cannot find differences in information responses between socio-economic groups.

JEL Classification: I20, D10, D83

Keywords: school quality, school choice, information, media

Corresponding author:

Pierre Koning

CPB Netherlands Bureau for Economic Policy Analysis

P.O. Box 80510

2508 GM The Hague

The Netherlands

E-mail: pwck@cpb.nl 


\section{Introduction}

Information on the quality of various public services is becoming more and more widespread. Hospitals publish mortality rates, local governments are ranked according to their perceived customer friendliness and schools receive quality scores based on their academic achievements. This trend allegedly improves the overall quality of public services, as the quality information benefits several stakeholders. It is assumed that managers of the public services are able to benchmark their performance to that of their competitors, taxpayers can hold these managers accountable for how their money is spent and last but not least consumers may make better informed choices.

So far, the empirical literature dealing with the effect of transparent quality information on school choice is limited. Examples outside of the education arena are Pope (2009) on hospital rankings and patient visits and Kling et al. (2008) on Medicare drug plan choice. Both papers conclude that easy-to-understand information does influence conscious choice behavior. Pope for example finds more non-emergency patient visits in hospitals ranked higher in a yearly study of the U.S. News \& World Report. Concerning school choice, the indirect effects of quality information on housing prices due to catchment areas ${ }^{1}$ are relatively well established using U.S. data (e.g. Downes and Zabel 2002; Figlio and Lucas 2004; Kane et al. 2006). There is less evidence on the direct effects of quality information on school choice behavior. Hastings, Van Weelden and Weinstein (2007) and Hastings and Weinstein (2008) are important contributions in this respect. Both papers study school choice of low- and middle income families in one particular public school district in North Carolina. The authors analyze an experiment in which under the No Child Left Behind act students at low-performing schools are given the opportunity to relocate to a different school and are provided with explicit quality information about the alternative

\footnotetext{
${ }^{1}$ Catchment areas provide preferential admission for inhabitant children to neighbourhood schools.
} 
schools. They find that this led to five to seven percentage points more parents choosing higher-scoring schools.

This paper uses unique data from the Netherlands on publicly available school quality scores to assess their actual effect on school choice behavior. ${ }^{2}$ Our paper contributes to the literature by investigating how secondary school choice of students from all socioeconomic groups in the Netherlands is affected by publicly available quality information. The Netherlands presents an interesting setting to study the direct effect of information on school choice. It is a densely populated country, so that within a ten kilometer radius a child can reach on average 11 relevant secondary schools. Negligible school fees, good public transport, and more importantly, unrestricted free school choice furthermore ensure that school choice reflects preferences more strongly than in countries with school catchment areas and heterogeneity in school fees. Moreover, extracurricular activities take place outside of the school environment, so that these possibilities do not affect school choice like in other countries.

Our data are unique on several levels. Rather than focusing on accountability programs initiated by the government, we assess the influence of school rankings published yearly since 1997 by national newspaper Trouw. Knowledge of these rankings among parents of children about to go to high school is relatively high, also because several regional newspapers copy the most relevant information for their readers into their issues. Trouw uses objective quality indicators from the Dutch Inspectorate for Education to calculate a final, overall quality score for each school track offered at each school. The newspaper corrects these scores for differences in the initial quality of students, by adjusting them for e.g. the percentage of children from cultural minorities. As in principle all secondary schools in the country feature in the Trouw publication, we can measure the effects of the quality scores on student inflow across the entire quality distribution of

\footnotetext{
${ }^{2}$ Koning and Van der Wiel (2010) use the same dataset to analyze how school boards respond to these quality rankings in terms of their subsequent quality performance.
} 
schools. By furthermore using country-wide administrative student records that include specific information on students' home addresses, the relative importance of quality scores versus distance from home can be investigated as well. Finally, as our individual level dataset also includes detailed information on household income and composition, we can moreover draw conclusions on differences in the responsiveness to quality information between socio-economic groups.

In our paper we draw complementary conclusions from both a longitudinal school level dataset and a cross-sectional individual level dataset. Using the school level dataset, we establish a causal effect of quality scores published by Trouw on the number of students entering a school in the year after publication. This effect can be interpreted as causal, as we control for school track fixed effects and exploit the substantial lag between the registration of quality indicators and their publication. It turns out that, as expected, negative school quality scores decrease the number of students choosing such schools, while positive quality scores significantly increase the inflow of students. Particularly the positive effect is strongest for academic school tracks which prepare for university (' $V W O$ '). When Trouw qualifies the academic track of a school as most positive, the inflow of students increases by 16 to 18 students in the year after the publication. This is a substantial effect, given that the average school track cohort size is 76 students. Presumably, the smartest and most ambitious students pay most attention to positive quality information. This confirms earlier research in this field. Hastings, Kane, and Staiger (2006) already showed that preference attached to schools' mean test score increases with neighborhood income and the student's own academic ability.

The results found in the analysis of individual school choice are in line with estimates obtained in the school level analysis. In particular, we use an administrative dataset of all first year secondary school students in the Netherlands to run conditional logit regressions on each student's relevant geographical choice sets. As we observe the 
characteristics of the chosen school and of the relevant alternative options within $20 \mathrm{~km}$ of the home address, it is possible to identify the effects of school quality scores. We find that the probability to choose a school is mainly driven by the traveling distance and its distance rank order, but the probability of attending a school is also significantly affected by its quality score in the predicted way. The estimates furthermore enable us to compute the implied 'willingness to travel' to well-performing schools, which reveals how important quality scores are relative to the traveling distance. This estimated willingness to travel turns out to be rather low. Students are only willing to travel about 220 meters more in order to attend a well-performing rather than an average school. As in the school level analysis, students who attend an academic school track show the highest inclination to attend a well-performing school. This raises the question whether this difference in quality response is driven by differences in cognitive ability and ambition - which determine each student's school track — or by socio-economic differences. As our dataset contains detailed household income and composition information, we can analyze this question in greater detail. In contrast to what those concerned with equity issues feared, no differences in quality response are found between socio-economic groups. The observed divergence in information response across school tracks can thus be attributed to variation in ability and ambition of the students attending. This suggests that at least within school tracks publicly available quality information does not increase inequity in the quality of education consumed.

This paper proceeds as follows. Section 2 introduces the Dutch institutional environment and Trouw's school quality scores in detail. Section 3 explains which schoollevel data and individual-level data is used in the empirical analysis. The empirical design is dealt with in Section 4, while the empirical results are presented in Section 5 of the paper. Section 6 concludes. 


\section{School choice and school quality in the Netherlands}

The Dutch Constitution guarantees freedom of education since 1848. Initially, freedom meant that every group of citizens was allowed to establish a school of their own religious, societal or educational beliefs. Since 1917 the Dutch state even finances these 'private' schools in the same way that it finances public schools that do not have a specific denomination. The Netherlands also has a long history in free school choice. Students can freely decide which primary, secondary and tertiary education outlets they wish to attend.

It rarely happens that students are declined access to their most preferred school: (random) selection is only possible in the rare event that a school receives substantial oversubscription or when parents' beliefs evidently deviate from those of the school. Free school choice in the Netherlands is often regarded as a rather unique phenomenon, because in practice there are few limitations to choosing a school other than the one which is located most closely (e.g. Bishop 1998; Dijkstra et al. 2004). School fees are negligible for both public and private schools, so that financial constraints are not binding. Children have on average 10 secondary schools that offer the relevant school track to choose from within a radius of 10 kilometers of their home address. Also, sport-, musical- and other extracurricular activities usually do not take place at the school but elsewhere. Parents can thus focus on measures of school quality other than the supply of these services when choosing a school.

In this paper, we direct our focus towards school choice behavior in secondary education because of the nature of this decision and the availability of data. First, the choice which high school to attend is made deliberately and simultaneously by (the parents of) all 12-year old children. More specifically, children in the final year of primary education have to wait for their 'school advice' in order to enroll at a secondary school. This advice is compiled by their primary school teacher, who relies on the child's test score on a 
centralized exam taken halfway through the year. Each student's school advice states which school track the teacher believes he or she is able to complete. A secondary school typically requires its prospective students to have a school advice that coincides with the school $\operatorname{track}(\mathrm{s})$ it offers. Over the years the categorization of school tracks has changed, but four broad categories can be distinguished that were constant over time. The most academically oriented school track (in Dutch: ' $V W O$ '), from which a diploma guarantees admission to universities, lasts six years. The middle level general school track (in Dutch: 'HAVO'), which guarantees admission to a 'hogeschool' (comparable to colleges), lasts five years. The lowest track that provides for a general education (in Dutch: ' $V M B O-g t$ ') lasts four years and prepares for vocational tertiary education. We limit our analysis to these three, ordinally classifiable tracks. We exclude the fourth track, dedicated to vocational training, as this contains such a large variety of schools (e.g. those focused on agriculture, on personal care or on children with special needs). Note that in the first and second year the vast majority of secondary schools offer multi-track classes.

Extensive data availability on both students and schools is the second reason to focus on secondary school choice in the Netherlands. Since 2009, Statistics Netherlands provides detailed administrative records for a random sample of Dutch high school students. These records include student home addresses (i.e. detailed postcode information) and household characteristics such as income and composition. In addition, a long panel dataset of schools can be constructed that includes publicly disclosed quality measures. This school-level dataset is based on school records from the Dutch Inspectorate of Education. It is augmented with composite school quality scores, which have been published yearly since 1997 by the national daily newspaper Trouw. We discuss both data sources in more detail in the next subsection.

Each fall Trouw publishes a list of schools that are stratified by province. Although the newspaper does perform its own calculations, the publication is based on the school 
records of the Inspectorate of Education. ${ }^{3}$ All four school tracks feature separately in the publication, so that a school that offers all tracks enters in four different locations with potentially different quality scores. Although the exact information presented by Trouw has changed from year to year, some variables were recurrent items for all years. First, this comprised background characteristics such as school size, religion and the percentage of children from cultural minorities. Second, three quality indicators are observed for all years. That is, the average grade students achieve at the centralized exam in their final year of education; the percentage of students who from third grade on leave the school with a diploma without any delay; and the net percentage of students who in third grade are within school tracks that are above or below their school advice. The registration of the last two indicators prohibits schools from 'gaming' their average grade results by either excluding low-performing students from final exams or by forcing students into lower school tracks. Figure A in the appendix shows an example excerpt of the Trouw publication in 2002.

Trouw calculates two overall quality scores by school track on the basis of the three objective performance indicators. ${ }^{4}$ First, a 'gross' overall quality score is determined using factor analysis. ${ }^{5}$ According to this estimate all schools are then distributed into five categories by school track (“--”, “-”,“0”, “+” or “++”) such that a multi-track school could potentially be in four different categories at one and the same time. Second, in order to provide a quality measure that is closer to the 'value added' by a school, the overall raw quality score is corrected for several factors correlated with the initial quality of students. This has typically been done in OLS regressions using the percentage of children from

\footnotetext{
${ }^{3}$ More information on the quality information that the Inspectorate registers and on the information that Trouw publishes can be found in Dijkstra et al. (2001). An initial assessment of the association between the Trouw scores and student inflow was done by Dronkers (1999).

${ }^{4}$ Koning and Van der Wiel (2010) explain the estimation procedures and how they have changed over time in more detail.

${ }^{5}$ Although the three performance indicators mentioned have always been included in the overall scores, other variables such as the percentage of delayed students were also included in several other years.
} 
cultural minorities as a control variable. ${ }^{6}$ In a similar fashion as for the unadjusted scores, five final quality scores are handed out, ranging from “---" to “++". Parents are probably most influenced by the adjusted scores, as these are prominently presented by Trouw as the final quality scores. Because these adjusted scores are furthermore copied by several regional newspapers for the relevant schools in their area, it is likely that parents are directly or indirectly aware of them when deciding on which school their children should attend.

There is a relatively long delay between the registration of the quality indicators by the Inspectorate of Education and the publication of the quality scores by Trouw. The appendix presents a time line in Figure B that shows the timing of the Inspectorate administration, the Trouw publication, and the actual school choice that is made by 12 -year old children. As the time line shows, there is a three year lag between the registration of data and the registration of the potential response to that information in terms of the number of new students at a school. This is because the Inspectorate takes about a year and a half to generate the school quality records, Trouw spends another six months to finalize its publication, and students are only observed at a school ten months after that.

Although the newspaper Trouw was the first media outlet to publish quality rankings of secondary schools, there are two other information sources parents could use. Following a change in policy, the Inspectorate of Education started publishing their own data on their website in 2000 . This means that the school quality cards can be reviewed for each school and school track separately. The way the information is presented however with relatively many details and without much clarification — makes it hard to compare quality across schools, especially because an overall measure of quality is absent. Next to this, the national weekly magazine Elsevier started publishing rankings in 2001 that are based on the same information from the Inspectorate that Trouw uses. A major difference

${ }^{6}$ The percentage of children from cultural minorities has always entered the correction equation, but did change in its definition several times. Other controls that have been included in certain years are the percentage of students from low-income households and the students' school advice. 
between the two publications is that, rather than single year measures, Elsevier takes threeyear moving averages of the quality indicators as inputs. We choose to focus on the Trouw scores in this paper, as the readership of Trouw is larger and as we have a longer panel for the Trouw score.

\section{Data}

\subsection{School level data}

The school level dataset that we use in our analysis is compiled by joining several information sources. We received 'quality cards' for each school and school track from the Inspectorate of Education for the years 1995-2006. These cards provided information on the XY-coordinates of a school, its religious denomination, the number of students, the percentage of students in each school track, the percentage of students from cultural minorities and each school track's quality indicators. As explained in the previous section, these objective quality indicators served as inputs for the overall Trouw quality scores. From Trouw we received a paper copy of each of their yearly school ranking publications from 1996 to 2008. As these scores were not stored electronically by Trouw, we manually added the final adjusted scores and the raw unadjusted scores to our dataset. ${ }^{7}$ For each municipality we furthermore added information on population size in the relevant age categories from Statistics Netherlands.

Our final dataset contains 7,542 yearly observations on schools recorded from 1996 to 2003 (but published with a delay of two years) and 12,828 observations on school tracks offered at these schools. 46 percent of schools offer all three tracks and 39 percent of schools just offer a single track. Unfortunately, we cannot use data from 1995, as all information was recorded at the school rather than at the school track level at that time.

\footnotetext{
${ }^{7}$ This was necessary as Trouw has used more detailed information from the Inspectorate to compute the scores than we had access to.
} 
Furthermore, in our empirical analysis we lose data on the three latter years as there is a three year lag between the recording of the objective quality measures and the recording of the number of students that could have responded to the publication of this quality information.

Table 1 presents descriptive statistics of the school level dataset for the different final quality scores. The sample includes a substantial number of observations for which the Trouw score is missing, which is mostly due to the fact that the school track has too few students. Trouw decided not to report a final score for (very) small schools, as the confidence intervals for grade and diploma results at these schools are considered too large to construct overall scores. The high standard deviation in average grades for this subgroup highlights this phenomenon. Trouw divides all other school tracks into five categories of distinctly different sizes. About one percent of observations with a final score is filed in the very worst category (“--”), another one percent in the very best category (“++”), about fifty percent of observations is classified as performing on average ("0") and the remaining school tracks are split between the badly (“-”) and well performing groups (“+”). As the classification is performed per separate school track, the differences in the distribution of the scores over the school tracks are negligible. For the school tracks that have received a final quality score, the average grades and the percentage of students that receive a diploma without delay increases monotonously with the score ranking, as expected. Finally, the last two rows of Table 1 show that there is substantial variation in score ratings per school track over time. In particular, the probability to receive the same ranking in the next year is on average about 50 percent and almost all school tracks have at least once received a neutral score. 


\begin{tabular}{|c|c|c|c|c|c|c|c|}
\hline & & \multicolumn{6}{|c|}{ Adjusted quality score by school track } \\
\hline & & Missing & $\begin{array}{r}\text { Most } \\
\text { negative }\end{array}$ & Negative & Neutral & Positive & $\begin{array}{r}\text { Most } \\
\text { positive }\end{array}$ \\
\hline & & N.A. & -- & - & 0 & + & ++ \\
\hline \multicolumn{2}{|l|}{ Observations } & 1,704 & 169 & 2,077 & 6,429 & 2,352 & 97 \\
\hline \multicolumn{2}{|l|}{ Academic track (' $V W O$ ') } & $12 \%$ & $1 \%$ & $16 \%$ & $50 \%$ & $20 \%$ & $1 \%$ \\
\hline \multicolumn{2}{|l|}{ Middle track ('HAVO') } & $15 \%$ & $2 \%$ & $17 \%$ & $47 \%$ & $18 \%$ & $1 \%$ \\
\hline \multicolumn{2}{|l|}{ Lowest track ('VMBO-gt') } & $13 \%$ & $1 \%$ & $16 \%$ & $52 \%$ & $17 \%$ & $1 \%$ \\
\hline \multirow[t]{2}{*}{ Total number of students } & Mean & 664 & 880 & 1,008 & 1,068 & 1,031 & 785 \\
\hline & St.dev. & 447 & 400 & 438 & 483 & 522 & 785 \\
\hline \multirow[t]{2}{*}{ Number of first year students } & Mean & 49 & 58 & 73 & 81 & 81 & 69 \\
\hline & St.dev. & 38 & 31 & 39 & 40 & 41 & 47 \\
\hline \multirow[t]{2}{*}{ Grade obtained in exams } & Mean & 6.3 & 6.0 & 6.2 & 6.4 & 6.5 & 6.6 \\
\hline & St.dev. & 0.38 & 0.22 & 0.25 & 0.22 & 0.25 & 0.33 \\
\hline \multirow[t]{2}{*}{ Diploma without delay } & Mean & $71 \%$ & $49 \%$ & $59 \%$ & $72 \%$ & $77 \%$ & $82 \%$ \\
\hline & St.dev. & 18.1 & 16.6 & 16.5 & 15.5 & 14.5 & 16.9 \\
\hline \multicolumn{2}{|c|}{ Probability to stay in category next year } & 0.60 & 0.09 & 0.33 & 0.61 & 0.36 & 0.09 \\
\hline \multicolumn{2}{|l|}{ Tracks that ever receive score } & $50 \%$ & $15 \%$ & $73 \%$ & $97 \%$ & $79 \%$ & $9 \%$ \\
\hline
\end{tabular}

\subsection{Individual level data}

For the individual choice analysis in this paper, we use a rather unique dataset on the cohort of students that entered the first year of secondary school in September 2003. The dataset combines the relevant school track information introduced in the previous subsection with information from two administrative datasets compiled by Statistics Netherlands. Using (recoded) social security numbers, we merged administrative records on the student level to administrative tax records on the level of the students' households that contain detailed information about household income and composition. Although in principle student records for all students in the country are administered, we received tax record data for about one third of the population. This is because - for budgetary reasons - Statistics 
Netherlands randomly selects only one third of observations from the tax authority's database.

For all first year students, we have constructed the relevant choice set of schools in their neighborhood. It is assumed that students limit their school searching behavior to one school track only, such that the school track that a student is observed in defines the choice set. For $26 \%$ of the children in our sample, we know this school track right away as they attend single track schools or are admitted to single track classes. We use administrative records from the academic year 2005/2006 to retrieve the school track of the students for which it could not be recovered directly, as in the third year of secondary school the vast majority of mixed-track classes have transitioned to single track ones. For about thirty percent of the students we however fail to retrieve the school track through this procedure, as their schools do not administer which school track their students are in before the final year. These students are therefore left out of the analysis. All in all, we have a sample of 23,923 first year students of which we know household income that chose to attend a school less than $20 \mathrm{~km}$ from home. Of these observations 7,430 students attend the most academic track, 7,176 students attend the middle general track and 9,317 students attend the lowest general track. On average, students have 29 school track options within $20 \mathrm{~km}$ of their home, resulting in 670,272 observed combinations of individuals and school tracks.

Table 2 shows descriptive statistics of the individual level data. Consistent with the national statistics produced by Statistics Netherlands, the percentage of female students is largest in the most academic track and lowest in the lowest track. The percentage of children from ethnic minorities decreases in the school track level. Out of the three tracks, the most academic one hosts most children from entrepreneurial families, whereas the least academic one hosts most children from households that receive government benefits. Measured in terms of household income quartiles, the distribution over the three school tracks is also consistent with official statistics. In particular, $43 \%$ of children attending the 
academic track are from households in the top income quartile, whereas this is only the case for $22 \%$ of children in the lowest general track. The average distance that children have to travel to get to their nearest school is between 2.3 and 2.9 kilometers, while the average distance to the school actually chosen ranges between 3.9 and 4.3 kilometers. This traveling distance is largest for the students that attend the most academic track and smallest for those attending the lowest general track. About $40 \%$ of children choose the secondary school that is closest to their home address, such that the majority of children choose to travel beyond.

\begin{tabular}{|c|c|c|c|c|}
\hline \multirow[t]{3}{*}{ Descriptive statistics of indiv } & student & et by school & ack attended & \multirow{3}{*}{$\begin{array}{r}V M B O-g t \\
\text { (Lowest general) }\end{array}$} \\
\hline & & VWO & HAVO & \\
\hline & & (Academic) & (Middle general) & \\
\hline \multicolumn{2}{|l|}{ Number of administrative records } & 25,764 & 24,640 & 31,978 \\
\hline \multicolumn{2}{|l|}{ Records with household income observed } & 8,549 & 8,389 & 10,991 \\
\hline \multicolumn{2}{|l|}{ Records with income and school choice observed } & 8,107 & 7,823 & 9,811 \\
\hline \multicolumn{2}{|l|}{ Full records, choice within $20 \mathrm{~km}$ observed } & 7,430 & 7,176 & 9,317 \\
\hline \multicolumn{2}{|l|}{ Final choice set of individuals and schools } & 194,834 & 184,655 & 290,783 \\
\hline \multicolumn{2}{|l|}{ Girls } & $53.3 \%$ & $52.1 \%$ & $50.6 \%$ \\
\hline \multicolumn{2}{|l|}{ Dutch ethnicity } & $84.6 \%$ & $83.6 \%$ & $79.9 \%$ \\
\hline \multicolumn{2}{|l|}{ Main income source: wages } & $73.4 \%$ & $74.4 \%$ & $72.0 \%$ \\
\hline \multicolumn{2}{|l|}{ Main income source: own business } & $22.3 \%$ & $20.0 \%$ & $19.2 \%$ \\
\hline \multicolumn{2}{|l|}{ Main income source: government benefits } & $3.0 \%$ & $4.2 \%$ & $7.3 \%$ \\
\hline \multicolumn{2}{|l|}{ Household income below 25th percentile } & $14.8 \%$ & $18.5 \%$ & $23.9 \%$ \\
\hline \multicolumn{2}{|l|}{ Household income above 75th percentile } & $42.0 \%$ & $30.4 \%$ & $21.8 \%$ \\
\hline \multirow[t]{2}{*}{ Number of schools in choice set within $20 \mathrm{~km}$} & Mean & 29 & 27 & 37 \\
\hline & St.dev. & 20 & 19 & 24 \\
\hline \multirow[t]{2}{*}{ Number of schools in choice set within $10 \mathrm{~km}$} & Mean & 11 & 9 & 12 \\
\hline & St.dev. & 8 & 8 & 10 \\
\hline \multirow[t]{2}{*}{ Minimum distance to a school } & Mean & 2.7 & 2.9 & 2.3 \\
\hline & St.dev. & 3.1 & 3.4 & 2.6 \\
\hline \multirow[t]{2}{*}{ Distance to school that is chosen } & Mean & 4.3 & 4.2 & 3.9 \\
\hline & St.dev. & 3.8 & 3.7 & 3.6 \\
\hline \multicolumn{2}{|l|}{ Students choosing closest school } & $36.4 \%$ & $41.9 \%$ & $40.1 \%$ \\
\hline
\end{tabular}




\section{Empirical implementation}

\subsection{School level data analysis}

This subsection explains how we identify a causal effect of school quality scores on school choice in the year after Trouw's publication. The dependent variable in this school level analysis is (a proxy for) the number of first year students at a particular school. We argue that this effect is causal, as we control for school (track) fixed effects and as the relevant quality scores are computed using lagged information. Estimating fixed effects is important because time constant omitted variables of school characteristics are likely to be positively correlated with both the number of students entering a school and the quality score the school receives. For instance, the reputation of a school based on its approach to teaching could be such a time-constant omitted variable. The better this reputation, the higher the number of students attending the school, but also the better the quality scores. Not controlling for such unobserved characteristics would yield estimates for the effect of quality scores on student numbers that are likely to be overestimated. ${ }^{8}$

Besides time-invariant omitted variables, time-varying omitted variables may also be positively correlated with the Trouw quality rankings. For example, we do not observe the composition of the school board that may well change over time. If parents are persuaded to choose a school because of a new management team and this team also influences the relevant quality scores positively, the quality score response would again be overestimated. In our analysis we avoid such endogeneity problems by exploiting the threeyear lag between the registration of quality information and the potential response to the information. As we have argued earlier, this lag consists of a two-year delay between the registration and publication of quality information and a delay of an additional year between the publication of Trouw and the observed school choice. The long lag breaks

${ }^{8}$ Column (II) in Table 8 shows the OLS estimates that correspond to those in our baseline fixed effect regression in column (I) in Table 3 . Indeed, the OLS estimates are typically much larger than those estimates using fixed effects.

16 
down any instantaneous correlation between omitted variables at time $t$ that influence both student inflow at time $t$ and the quality score published at time $t-1$.

We estimate fixed effect regressions on two levels of data: school track fixed effect regressions of the number of first year students in each track and school fixed effect regressions on the total number of first year students at a school. The advantage of these two levels is that their results enable us to address spillover effects of the quality scores on the inflow into other school tracks within the same school. That is, school tracks may benefit from good scores that other school tracks have received. The school track fixed effect regressions measure the effect of the school track quality scores on student numbers as directly as possible. We do however not directly observe the number of first year students in each school track, as many schools only offer mixed-track first year classes. Therefore we proxy the number of first year students within a track in academic year $t$ by the number of third year students in each track in period $t+2$. Per school track, we thus lose two yearly observations. The number of first year students is moreover observed with a measurement error, as in two years time the school track cohort will have lost and/or added some students. We will assume that this measurement error is random, so independent of the other variables in the regression. This means the measurement error only affects the efficiency, and not the consistency, of our estimates. Besides the school track regressions, we estimate school level fixed effect regressions of the total number of new first year students at each school. The dependent variables in those regressions are (among others) the quality scores that each school track within that school has received. Although the estimated effects are less straightforward to interpret, this procedure gains two years of information and leaves room for spillover effects between one school track's score and the inflow into other tracks. We will explain both procedures in more detail below. 
The above arguments on endogeneity and the unit of analysis are formalized by specifying equation (1). The number of first year students $y$ for schools $i$, school tracks $j$ and time periods $t$ serves as our dependent variable:

$$
y_{i j t}=\sum_{r=--}^{++} \alpha^{\prime} R_{r, i j, t-3}+\chi^{\prime} N A_{i j, t-3}+\lambda^{\prime} x_{i j t}+\kappa^{\prime} x_{i j, t-3}+\sum_{t=1996}^{2001} \gamma^{\prime} T_{t}+v_{i j}+\varepsilon_{i j t}
$$

In the equation, all $R_{r}$ 's are dummies representing the occurrence of quality scores $r$ per school track $j$. The dummy "NA" equals one if no quality score is provided for school track $j$ at school $i$. The $x$ variables represent time varying controls from this period or the period in which the quality information was recorded. The $x$-variables include market size proxies like the size of the adolescent population in the municipality and the number of schools in the municipality at time $t$, but also school characteristics at time $t-3$ such as the total number of students that attended the school ${ }^{9}$, the number of branches of the school management, the percentage of students in each school track and the percentage of children from cultural minorities. ${ }^{10}$ We also include all (yearly) time dummies $T$. As we are estimating school track fixed effects, there are two separate error terms: the time-invariant school track specific term $v_{i j}$ and the error term $\varepsilon_{i j \mathrm{t}}$, which we assume to be i.i.d. $\left(0, \sigma_{\varepsilon}^{2}\right)$. In the school track regressions we furthermore correct our standard errors for clustering at the school level.

It is possible to aggregate equation (1) over all school tracks to the level of schools, resulting in equation (2). The total number of new first year students $y$ for schools $i$ and time periods $t$ is the dependent variable in this equation:

\footnotetext{
${ }^{9}$ One could worry about the fact that students at $t-3$ are a function of lagged dependent variables, causing our within estimator to be inconsistent. We have estimated models with and without the number of students at $t-3$ as an independent variable and the quality score estimates are somewhat stronger when we leave the number of students out.

${ }^{10}$ It should be noted that the definition of cumi-students has changed in 2003 and in 2005 . The average value of this variable is therefore not presented in Table 1. In the estimation of our models, we also control for this variable by allowing its impact to vary from year to year.
} 
$y_{i t}=\sum_{j=1}^{3} \sum_{r=--}^{++} \beta_{j}^{\prime} R_{r i j, t-3}+\sum_{j=1}^{3} \delta_{j}^{\prime} N A_{i j, t-3}+\pi^{\prime} x_{i j t}+\vartheta^{\prime} x_{i j, t-3}+\sum_{t=1996}^{2003} \tau^{\prime} T_{t}+v_{i}+\eta_{i t}$.

The quality scores $R_{r i j, t-3}$ and the dummy for an unknown score enter for each school track $j$ separately. The $x$ and $T$ variables represent the same controls as in (1). As equation (2) follows from adding up equation (1) over the school tracks, we can check for spillover effects of school track scores on the inflow at other school tracks within the same school. In particular, if there are no spillover effects of the quality score of school track $j$ on the inflow of students in school track $l$, for $l \neq j$, we would estimate $\alpha=\beta$ and $\chi=\delta$. The error term in equation (2) consists of two components: the time-invariant school specific term $v_{i}$ and the i.i.d. error term $\eta_{i t}$. As a result of the summation over school tracks, the two error components both consist of the sum of the school track error terms represented in (1) so that

$v_{i}=\sum_{j=1}^{J} v_{i j}$

and $\eta_{i t}=\sum_{j=1}^{J} \varepsilon_{i j t}$

As we use a within group estimator, the $v_{i}$ drops out of the estimation, implying that its composition is of no consequence. The matter is a bit more complicated for the composition of $\eta_{i t}$. There would be no problem if the covariance between $\varepsilon_{i j t}$ and $\varepsilon_{i l t}$ is equal to zero for $l \neq j$. As it is however likely that the covariance of the error terms within each 
school is positive, the random error term could have a larger variance. Although the efficiency of estimates diminishes because of this, it will not render them inconsistent.

In the empirical results section of this paper, one additional specification and two robustness checks of the school-level analysis are presented. We examine the causal effect of quality scores on the percentage of new first year students in a school-track fixed effect regression using the logarithm of $y_{i j t}$. The robustness checks estimate school track regressions with two additional regressors: Trouw's unadjusted quality scores based on data from $t-3$ and Trouw's final quality scores based on data from $t-2$. The rationale for these checks is explained more thoroughly in the next subsection.

\subsection{Individual level data analysis}

In this subsection, we consider the role that publicly available information plays in the school choice process of students and parents in more detail. In particular, the individual level analysis addresses two issues that cannot be touched upon with the school- and school track-level estimation results. First, special interest lies in the relative importance of quality scores versus distance from home. Second, the individual data allow us to estimate potential differences in the responses of socio-economic groups to quality scores. For this purpose, we estimate conditional logit regressions on the set of schools that children could have chosen. We define this set to consist of all schools that offer the school track relevant to the student that lie within $20 \mathrm{~km}$ of the child's home address. ${ }^{11}$ As we have data on a random sample of all children in the Netherlands, there is considerable variation in the choice sets future secondary school students face.

The starting point for the conditional logit analysis is the assumption that students and their parents choose the school that maximizes their utility. The utility that each school generates for a student is in part determined by characteristics of the school and in part by a random error component that differs by student and school. In certain specifications,

\footnotetext{
${ }^{11}$ This range is altered as a robustness check in the next section.
} 
interaction terms of the school characteristics with individual characteristics will also contribute to the utility function. Note that the conditional logit model assumes equal preferences for all students with identical characteristics. We prefer this easy-to-interpret method above random preference models, because we lack longitudinal data per child on its school choice. This is a common problem when investigating school choice, as most children only choose a secondary school once in their life.

In a conditional logit regression, the probability that a child $c$ chooses school $i$ is given by equation (3):

$$
p_{c i}=\operatorname{Pr}\left[y_{c}=j\right]=\frac{\exp \left(\sum_{r=--/}^{+/++} \beta_{r}^{\prime} R_{r c i(t-3)}+\delta^{\prime} N A_{c i(t-3)}+\kappa^{\prime} d_{c i}+\lambda^{\prime} z_{c i}\right)}{\sum_{k_{i}=1}^{K_{i}} \exp \left(\sum_{r=--/-}^{+/++} \beta_{r}^{\prime} R_{r c i(t-3)}+\delta^{\prime} N A_{c i(t-3)}+\kappa^{\prime} d_{c i}+\lambda^{\prime} z_{c i}\right)} .
$$

in which each $R_{c i}$ represents a dummy for the quality score given to each school that child $c$ considers. The dummy "NA" equals one if no quality score is provided for the relevant school track at school $i$ in the choice set of student $c$. The key control variable is the distance from home to each school, $d_{c i}$. The set of $x$ variables also includes seven dummies for different categories of the relative distance rank order of the school and several school characteristics recorded at time $t-3$ such as the total number of students that attended the school, the total number of first year students, the number of branches the school management operated, the percentage of students in each school track and the percentage of children from cultural minorities. It is important to control for school size as it is likely that students are more familiar with large schools through informal networks and more extensive marketing. The probability of choosing such a school will thus also be larger. We use standard maximum likelihood to estimate the parameters in the model. 
The estimates for the coefficients of the quality score dummies $(\beta)$ and the coefficient of the distance variable $(\kappa)$ are useful in order to determine the implied 'willingness to travel' to a school of a certain quality. ${ }^{12}$ The willingness to travel to a school of a quality $r$ rather than to a similar school of quality $s$, where $r \neq s$, is given by equation (4).

$W t t_{r}=-\frac{\hat{\beta}_{r}}{\hat{\kappa}}$.

This expression measures the relative importance of the quality score versus the importance of distance. The higher the willingness to travel to a well-performing school, the more important is the role quality information plays in the school choice process. The delta method is used to estimate the pertaining standard errors.

In certain specifications of equation (3), the $x$-variables also include interactions of the quality score and distance variables with certain individual characteristics. These interaction terms enable us to examine potential differences in the responsiveness of certain groups to different school characteristics. In the empirical section, we choose to focus on interactions with household income groups, dummies for the most important income component and the ethnicity of the child.

\subsection{Identification issues and robustness checks}

When estimating the $\beta$ s in the individual school choice analysis, there are two potential sources of endogeneity. First, the choice set of students can be endogenous if parents are free to choose where to locate their families. Second, like in the school level analysis, school quality scores can be correlated with omitted variables such as the reputation of a school.

\footnotetext{
${ }^{12}$ It should be noted here that, as a result of including the distance rank order dummies, the willingness to travel coefficients presented in Table 6 are conditional on the rank order of each school.
}

22 
To start with, the endogenous location decision could lead to an overestimation of the effect of distance on school choice and to an underestimation of the effect of the quality scores. This would stem from the fact that parents choose to live close to schools with high quality rankings. Although we have to keep in mind that our estimates are conditional on the location decision of parents, the endogeneity of location is largely irrelevant in the Dutch context. First, the high density of secondary schools in our sample (on average 31 schools within $20 \mathrm{~km}$ and 11 schools within $10 \mathrm{~km}$ of the home address) generates diverse choice sets. This means that the proximity to a school with a positive quality score is often compensated by the proximity of a school with a negative quality score. As long as there is sufficient quality diversity, we are able to estimate the relative effect of quality scores in our conditional logit regressions. Second, it is not likely that the Trouw quality assessment is an important driver of moving behavior of parents. Mobility in the Netherlands is generally low because of rental restrictions, property transfer taxes and cultural preferences for specific areas. Each year only 4 percent of individuals move from one municipality to another (Source: Statistics Netherlands, 2009). Using the administrative student records, we also observe that the percentage of children that moves is constant over the ages seven to fifteen. If parents base their location decision on Trouw, we would expect a higher probability of moving at ages eleven and twelve. Moreover, it should be stressed that the variability in Trouw quality scores for a given school track at a given school is high from one year to the next. In particular, in our sample the probability that a school track receives a different score next year is 0.47 . Given this large variance it is unlikely that households are willing to pay high transfer costs in order to live close to a school with a high Trouw score. Thus, all in al we argue that endogeneity problems due to location decisions will be limited in our specific analysis.

Endogeneity concerns can also arise in the individual level analysis because we do not control for time-invariant variables that are correlated with the adjusted Trouw quality 
scores and with school choice. Typically, school choice is largely driven by the reputation of a school, which we do not observe. Given that each child chooses a secondary school only once, we cannot resort to a fixed effect approach to solve this problem, as we did in the previous subsection. However, we can perform robustness checks by estimating the effects on school choice of variables that are expected to proxy the reputation of schools. If adding such controls does not alter the coefficient estimates for the final Trouw scores, this would suggest that the publication of these quality scores has a true effect on school choice. We propose both the unadjusted Trouw score and the adjusted Trouw score based on school performance two years rather than three years ago as appropriate variables for such robustness checks.

As explained in Section 3, per school track newspaper Trouw publishes both an overall quality score which is unadjusted for student composition, and a final adjusted score. The adjusted score partially corrects for the initial quality of the students entering the school and is presented much more prominently in the publication. It is however likely that the correlation between the unadjusted score and factors such as reputation is higher than that between the Trouw final score and reputation. Prejudice towards schools with many immigrant children might play a role, but also prejudice towards schools that are typically chosen by children from higher socio-economic groups. In a conditional logit regression of school choice on both the final scores and the unadjusted scores, we can thus check how the two estimates compare. If the estimated coefficients for the unadjusted scores are smaller and less significant, we may conclude that overestimation because of confounding factors is not a particularly large problem.

The other indicator that we include as a robustness check is the Trouw score that is published right after students have chosen their secondary school. We argued in the previous section that there is a three year lag between the registration of quality data and the observed response by students. A few months after the students first enter their new 
school, Trouw publishes a new quality ranking, based on two-year old information. It is likely that omitted variables show a stronger correlation with this two-year old information than with the three-year old information. We can check whether the inclusion of the more recent quality scores diminishes the estimates for the three year lagged scores. If not, we are confident that the actual publication of quality information in Trouw matters for school choice.

\section{Empirical results}

\subsection{School level data results}

In this subsection, we establish a causal effect of publicly available quality information on the number of students choosing a school in the Netherlands. The results of the school level analysis are shown in Tables 3 and 4. Baseline estimates according to school-track level equation (1) are presented in the first four columns of Table 3. Column I presents estimates for all school tracks together, whereas the other three columns focus on one of the three particular school tracks. Baseline estimates according to school-level equation (2) are presented in the last column of Table 3, with the quality scores for different school tracks entering separately. Table 4 presents robustness checks of the school-track level results. 


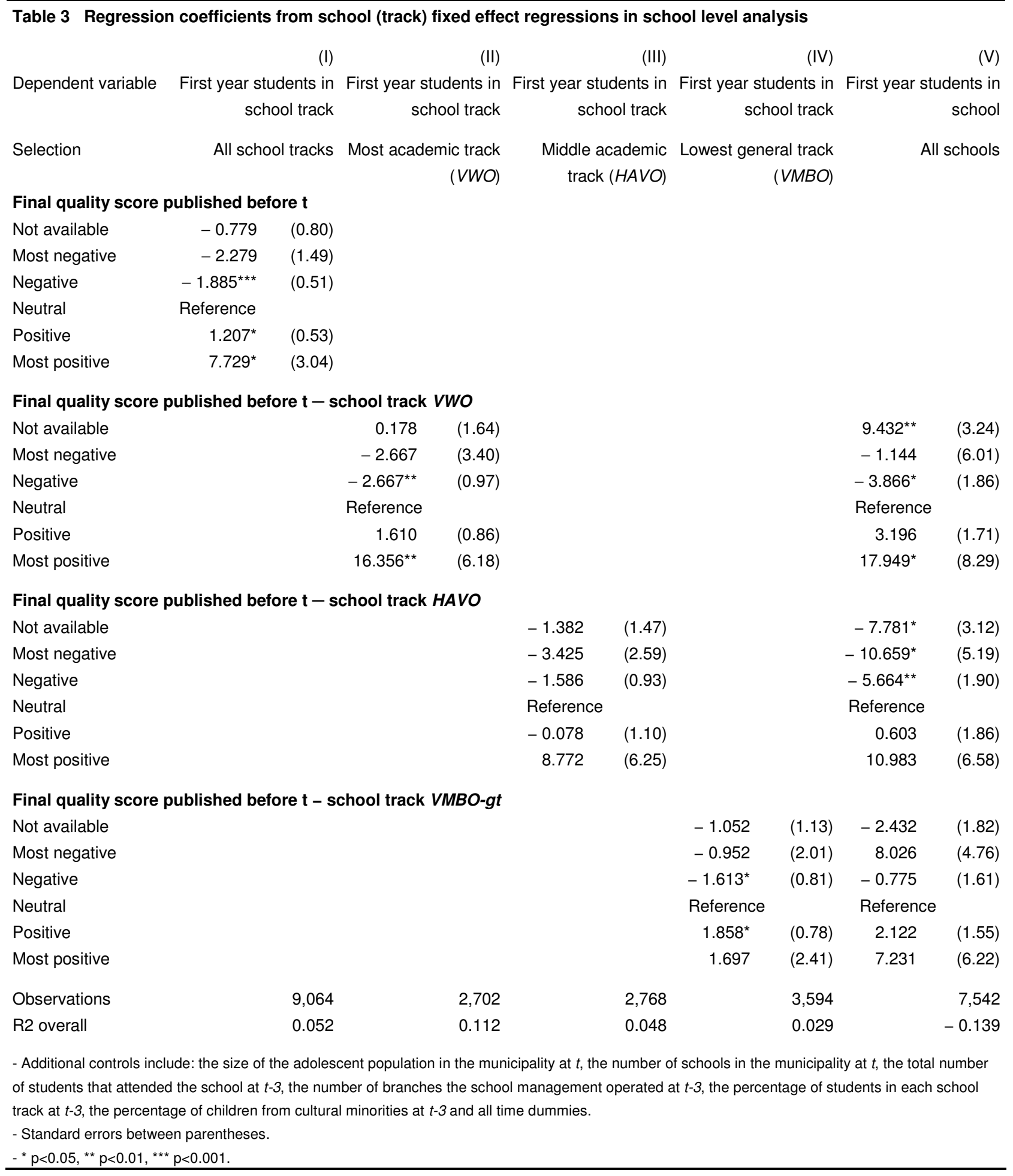

The five columns in Table 3 present regression coefficients for Trouw's final quality scores. The first column shows that there is indeed a significant, albeit small, effect of the quality scores on the number of students that enroll at that particular track. The 
school track cohort of new first year students is estimated to be two students smaller when a track scores a minus (“-”) compared to a track that receives a neutral score. We find the cohort of new students to grow by one student when a school track scores a plus (“+”). These are small effects, compared to the average number of 76 first year students attending a school track. The largest effect is found when Trouw qualifies a school track as excellent (“++"), with eight more students attending the particular school track in the year after Trouw's publication. When evaluating the estimates for the separate school tracks, the quality information response is largest for the most academic school tracks (column II). We estimate that sixteen more students choose a school in the most academic track in the year after Trouw has given it a "++" ${ }^{13}$ No significant effects are obtained for the middle academic track, while two small, yet significant coefficients are obtained for the lowest general track.

Column V in Table 3 presents the coefficient estimates for school fixed effects regressions of the total number of new first year students at each school, instead of using school track fixed effects. ${ }^{14}$ Recall from the previous section that these results help us in detecting potential spillover effects of school track quality scores on the inflow of students into other school tracks. When comparing the academic school track results from Column II to the academic track coefficients in Column V, the coefficient estimates appear very similar, although somewhat smaller. As explained in Section 4.1, the measurement error in the school track dependent variable may lead to underestimation of the quality information effects. The similarity between the estimates in Column II and Column V suggests that there are little spillover effects between the quality scores of the most academic school track and student inflow into other school tracks. We do find spillover effects for the

\footnotetext{
${ }^{13}$ A larger effect is found when focusing on schools that only offer the most academic track. The response in terms of student numbers is minus twelve when such a school scores a minus, and plus 28 when such a school scores a double plus.

${ }^{14}$ Note that the estimates of the dummies stating that the quality score is 'Not available' combine the effects of a quality score not being available for a certain school track and the school track not being available at all. This renders these estimates less comparable across rows.
} 
middle academic school track however, as there are significant differences between the estimates in Column III and those in Column V. Although the direct effects of the HAVO quality scores on new student numbers are limited, the inflow of students into other school tracks seems negatively affected by negative quality scores for this school track. We estimate that eleven students less choose to attend a school after its HAVO department has received a “--", while six students less choose a school after the middle academic track was awarded a single "-". There are no significant effects on the school level for the quality scores of the lowest level school track. This confirms our earlier finding that information responses are confined to the most academic track.

Table 4 presents additional school track level regressions in order to establish the robustness of the effect of quality information on collective school choice. Column VI presents coefficients estimated in school track fixed effects regressions of the log of new first year student numbers. This column hence shows the student number effects of the quality scores, which are proportional to the average size of the new cohort. When a track scores a "-", three percent less students attend the track in the year after, while two percent more student attend the track after it has received a "+". The largest relative effect is found when a school track is rated as excellent (“++”): the group of new first year students then grows by eleven percent. 


\begin{tabular}{|c|c|c|c|}
\hline & $(\mathrm{VI})$ & (VII) & (VIII) \\
\hline Dependent variable & $\begin{array}{r}\text { Log first year students } \\
\text { in school track }\end{array}$ & $\begin{array}{r}\text { First year students in } \\
\text { school track }\end{array}$ & $\begin{array}{r}\text { First year students in } \\
\text { school track }\end{array}$ \\
\hline Selection & All school tracks & All school tracks & All school tracks \\
\hline \multicolumn{4}{|c|}{ Final quality score published before $t$} \\
\hline Not available & $\begin{array}{r}-0.013 \\
(0.02)\end{array}$ & $\begin{array}{r}-0.352 \\
(0.97)\end{array}$ & $\begin{array}{r}-1.099 \\
(0.83)\end{array}$ \\
\hline Most negative & $\begin{array}{r}-0.042 \\
(0.03)\end{array}$ & $\begin{array}{r}-2.075 \\
(1.48)\end{array}$ & $\begin{array}{r}-1.923 \\
(1.54)\end{array}$ \\
\hline Negative & $\begin{array}{r}-0.027^{\star \star \star} \\
(0.01)\end{array}$ & $\begin{array}{r}-1.691^{\star *} \\
(0.55)\end{array}$ & $\begin{array}{r}-1.914^{* * *} \\
(0.52)\end{array}$ \\
\hline Neutral & Reference & Reference & Reference \\
\hline Positive & $\begin{array}{r}0.018^{*} \\
(0.01)\end{array}$ & $\begin{array}{l}1.100 \\
(0.57)\end{array}$ & $\begin{array}{l}1.371^{*} \\
(0.55)\end{array}$ \\
\hline Most positive & $\begin{array}{r}0.106^{* *} \\
(0.04)\end{array}$ & $\begin{array}{c}7.451^{*} \\
(2.97)\end{array}$ & $\begin{array}{r}7.299^{*} \\
(3.05)\end{array}$ \\
\hline \multicolumn{4}{|c|}{ Unadjusted quality score published before $t$} \\
\hline Not available & & $\begin{array}{r}-1.200 \\
(1.23)\end{array}$ & \\
\hline Most negative & & $\begin{array}{r}-1.207 \\
(2.03)\end{array}$ & \\
\hline Negative & & $\begin{array}{r}-0.920 \\
(0.92)\end{array}$ & \\
\hline Neutral & & Reference & \\
\hline Positive & & $\begin{array}{r}-0.354 \\
(0.71)\end{array}$ & \\
\hline Most positive & & $\begin{array}{l}0.908 \\
(1.35)\end{array}$ & \\
\hline \multicolumn{4}{|c|}{ Final quality score published after $t$} \\
\hline Not available & & & $\begin{array}{r}-2.669^{\star \star *} \\
(0.81)\end{array}$ \\
\hline Most negative & & & $\begin{array}{l}2.207 \\
(1.57)\end{array}$ \\
\hline Negative & & & $\begin{array}{r}-1.100 \\
(0.56)\end{array}$ \\
\hline Neutral & & & Reference \\
\hline Positive & & & $\begin{array}{l}1.513^{*} \\
(0.61)\end{array}$ \\
\hline Most positive & & & $\begin{array}{r}-1.083 \\
(1.94)\end{array}$ \\
\hline Observations & 9,064 & 9,064 & 9,064 \\
\hline $\mathrm{R} 2$ overall & 0.038 & 0.052 & 0.056 \\
\hline \multicolumn{4}{|c|}{$\begin{array}{l}\text { - Additional controls include: the size of the adolescent population in the municipality at } t \text {, the number of schools in the municipality at } t \text {, the total } \\
\text { number of students that attended the school at } t-3 \text {, the number of branches the school management operated at } t-3 \text {, the percentage of students in } \\
\text { each school track at } t-3 \text {, the percentage of children from cultural minorities at } t-3 \text { and all time dummies. } \\
\text { - Standard errors between parentheses and }{ }^{*} p<0.05,{ }^{* *} p<0.01,{ }^{* * *} p<0.001 \text {. }\end{array}$} \\
\hline
\end{tabular}


Columns VII and VIII present coefficients from school track fixed effects

regressions with additional quality variables that theoretically have a larger correlation with unobserved factors such as the reputation of a certain school track. The estimates in Column VII include those for the unadjusted quality scores that Trouw publishes, next to the final scores that we have focused on so far. As explained in Section 2, the final scores correct for the initial quality of inflow to some extent, while the unadjusted scores do not.

Column VII shows that the response to the unadjusted scores is insignificant and much smaller than to the final scores.

The second robustness check in Column VIII yields estimates of a school track regression that includes both the final Trouw scores published in the year before students pick a school, as well as those published right after students have already chosen their school. Although there cannot be a direct effect of the later publication on school choice, it is likely that the correlation between the data underlying the Trouw scores in $t+1$ (gathered at $t$-2) and unobserved factors determining school choice at time $t$ is substantial. However, the relevant Trouw score estimates in Column VIII are almost identical to those in the original specification (i.e. Column I), whereas the estimates of the scores published at $t+1$ are smaller and less significant. These robustness checks thus again confirm the general finding that parents pay attention to the newspaper quality scores when choosing a school for their child.

\subsection{Individual level data results}

This subsection analyzes the quality information effects on individual school choice in more detail. By assessing individual school choice behavior, we can provide more insight into the relative importance of Trouw's quality scores and into differences in quality responses between socio-economic groups. Table 5 contains estimated odds ratios obtained from conditional logit regressions of school choice on the characteristics of all schools that 
offer the relevant school track within 20 kilometers of each child's home address. This table shows how the probability of choosing a school track is affected by the distance parameters and the quality scores. Table 6 uses the coefficient estimates in the same regressions to present the implied 'willingness to travel' to schools with certain quality scores. This table gives an idea of the importance of quality scores vis-à-vis other school characteristics such as distance. Note that Table $\mathrm{A}$ in the appendix presents coefficient estimates of extended conditional logit regressions that include interactions of both distance and school quality with various socio-economic characteristics of students. In these extended models, any differences in the quality score response between socio-economic groups should show up in the interaction term estimates. Table 7 finally presents sensitivity checks on the conditional logit regressions from Table 5 .

The odds ratios that are shown in Table 5 are for the full sample (Column I), for the most academic school track only (Column II), for the middle academic school track only (Column III) and for the lowest general school track only (Column IV). In all four regressions, the distance to a school in kilometers and the distance rank order of a school are the most important determinants of school choice. These two factors explain between 89 (for academic track students) and 98 percent (lower track students) of the 46 percent of choice behavior that is explained by observed characteristics. The first row in Table 5 starts out with the average unconditional probability of a school being chosen in each of the regressions. These base probabilities - ranging from 3 to $4 \%$ - are useful to interpret the size of the odds ratios below. In the first column the probability of a school being chosen goes down by 31 percent for each kilometer it is located further away from the child's home address. Our preferred specification of the distance variable is linear, as quadratic and non-linear specifications did not add much explanatory power and the interpretation of willingness to travel coefficients is more straightforward. The distance rank order of a school is included in our regressions to control for the difference in school density between 
students' choice sets. In all columns, the odds ratios of the distance rank order of a school consistently decrease from the closest school until the school that is further away than 14 others (15th rank order). For the entire sample, the probability of choosing a school that is the 2 nd or 3 rd closest to home is 15 percent smaller than choosing the closest school, ceteris paribus.

The school quality indicators do matter for individual school choice, particularly when analyzing all school tracks together. According to our estimates, a school that has been ranked most negatively (“--”) is 27 percent less likely to be chosen compared to an identical school that receives a neutral quality score, whereas a school that has been ranked moderately negatively (“-”) is 12 percent less likely to be chosen. Good quality scores increase the likelihood a school track is chosen, with schools scoring well (“+”) being 9 percent more likely to be chosen. We do not find a significant effect for the most positive quality score (“++"), although an odds ratio larger than one is consistent with more students attending a school. When looking at the different school track samples separately, a positive quality score only generates an odds ratio significantly different from one for the most academic school track. This confirms our findings for the school level analysis. Column II shows that students are 13 percent more likely to pick an academic school track that scores a “+”, compared to an identical academic school track with a neutral score. Column III shows that the probability of choosing a school of the middle academic track that is graded most negatively (“--") is small. For school choice in the lowest general track, it matters whether the school received a negative quality score. The estimated probability of choosing a $V M B O$ school that received the most negative ranking is 28 percent lower than the probability of choosing a neutral scoring school and the probability of choosing a school that received a single "-" is 15 percent lower. 
Table 5 Odds ratios from conditional logit regressions in individual level analysis

(l)

Dependent variable School choice within

$20 \mathrm{~km}$

School ch

(II)

Selection

All first year students
$20 \mathrm{~km}$

School choice within

$20 \mathrm{~km}$

Students in most academic track
Students in middle academic track
(IV)

School choice within

$20 \mathrm{~km}$

Students in lowest

general track

Average unconditional probability of choosing a school

0.035

0.038

0.039

0.032

Distance from home address to school in kilometers

\begin{tabular}{|c|c|c|c|}
\hline $0.685^{* * *}$ & $0.678^{* * *}$ & $0.666^{* * *}$ & $0.696^{* * *}$ \\
\hline$(0.005)$ & $(0.009)$ & $(0.010)$ & $(0.008)$ \\
\hline
\end{tabular}

Rank order distance from home address to school

$1^{\text {st }}$

$2^{\text {nd }}$ to $3^{\text {rd }}$

Reference

Reference

$0.833^{* * *}$

Reference

Reference

$0.811^{\text {*** }}$

$0.875^{\star * *}$

(0.019)

(0.035)

(0.035)

(0.030)

$4^{\text {th }}$ to $6^{\text {th }}$

$0.634^{\text {*** }}$

$0.629^{\text {*** }}$

$0.628^{* * *}$

$0.632^{\text {*** }}$

(0.029)

(0.052)

(0.055)

(0.046)

$7^{\text {th }}$ to $10^{\text {th }}$

$0.463^{\star * *}$

$0.480^{\star * *}$

$0.484^{\star * *}$

$0.444^{* * *}$

(0.042)

(0.074)

$(0.082)$

(0.065)

$11^{\text {th }}$ to $15^{\text {th }}$

$0.382^{\star \star *}$

$0.383^{* * *}$

$0.481^{* * *}$

$0.342^{* * *}$

(0.110)

(0.091)

$16^{\text {th }}$ to $21^{\text {st }}$

$0.393^{* * *}$

$0.443^{\star \star *}$

(0.074)

(0.135)

$0.551^{\text {*** }}$

$0.457^{\star \star *}$

$0.351^{\text {***}}$

(0.145)

(0.114)

$22^{\text {nd }}$ and beyond

$0.472^{* * *}$

(0.156)

$0.692^{*}$

$0.370^{* * *}$

$(0.127)$

Final quality score published before $\mathbf{t}$

\begin{tabular}{|c|c|c|c|c|}
\hline \multirow[t]{2}{*}{ Not available } & $0.700^{* \star \star}$ & 0.998 & 1.125 & $0.651^{\star \star \star}$ \\
\hline & $(0.032)$ & $(0.062)$ & $(0.061)$ & $(0.052)$ \\
\hline \multirow[t]{2}{*}{ Most negative } & $0.727^{\star *}$ & N.A. ${ }^{\#}$ & $0.586^{*}$ & $0.719^{*}$ \\
\hline & $(0.123)$ & & $(0.217)$ & $(0.154)$ \\
\hline \multirow[t]{2}{*}{ Negative } & $0.880^{\star \star \star}$ & 0.995 & 0.934 & $0.854^{\star \star \star}$ \\
\hline & $(0.025)$ & $(0.047)$ & $(0.044)$ & $(0.039)$ \\
\hline Neutral & Reference & Reference & Reference & Reference \\
\hline \multirow[t]{2}{*}{ Positive } & $1.088^{\star \star \star}$ & $1.130^{* *}$ & 1.057 & 1.049 \\
\hline & $(0.022)$ & $(0.040)$ & $(0.040)$ & $(0.038)$ \\
\hline \multirow[t]{2}{*}{ Most positive } & 1.082 & 0.940 & 1.186 & 0.937 \\
\hline & $(0.082)$ & $(0.108)$ & $(0.360)$ & $(0.145)$ \\
\hline \multicolumn{5}{|c|}{ Percentage of children from cultural minorities } \\
\hline & $0.984^{* * *}$ & $0.993^{*}$ & $0.990^{* * *}$ & $0.987^{* * *}$ \\
\hline & $(0.001)$ & $(0.003)$ & $(0.002)$ & $(0.002)$ \\
\hline Observations & 670,272 & 194,834 & 184,655 & 290,783 \\
\hline $\mathrm{R} 2$ & 0.46 & 0.46 & 0.47 & 0.46 \\
\hline \multicolumn{5}{|c|}{ " ${ }^{\prime}$ In 2003, no VWO-schools were classified as performing in this category. } \\
\hline \multicolumn{5}{|c|}{$\begin{array}{l}\text { - Additional controls include: the total number of students that attended the school at } t-3 \text {, the total number of first year students at } t-3 \text {, the } \\
\text { number of branches the school management operated at } t-3 \text { and the percentage of students in each school track at } t-3 \text {. } \\
\text { - Standard errors of coefficients in parentheses and }{ }^{*} p<0.05,{ }^{* *} p<0.01,{ }^{* * *} p<0.001 \text {. }\end{array}$} \\
\hline
\end{tabular}


Table 5 also shows the odds ratio of the percentage of children from cultural minorities. Each additional percent of children from cultural minorities in the school track decreases the probability of choosing the school by one to two percent. In more detailed regressions we however found a strong opposite result for children that are not of Dutch origin who actually prefer going to schools with many students from cultural minorities. This effect is substantial as the average school has six percent of students from cultural minorities (ranging from four percent in the academic track and seven percent in the lowest track). Note that the standard errors for this variable are small, so that this is a very robust finding.

Table 6 presents the implied 'willingness to travel' (WTT) towards schools with certain quality scores that is inferred from coefficient estimates of the conditional logit regressions. These willingness to travel estimates indicate how important other school characteristics are, compared to the traveling distance. Note that each WTT should be interpreted ceteris paribus, so that it is also conditional on the rank order category of a school. The estimates in Table 6 represent the willingness to travel to an average school, so that there is a positive WTT for negative quality scores and a negative WTT for positive quality scores. The table highlights that given that the average distance to the chosen school is about four kilometers in our sample, the traveling distance outweighs school quality scores in the individual school decision. The largest (significant) distance students are willing to travel (in Column I) is 844 meters, so as to avoid a school that is considered of the most negative quality. The smallest estimated distance that students are willing to travel is 222 meters, so as to attend a school that is considered of a positive quality. ${ }^{15}$

\footnotetext{
${ }^{15}$ In order to assess the value of this number, we compare it to another school track characteristic that students and parents care about: the percentage of children from cultural minorities. It is estimated that students are also willing to travel 222 meters to attend a school with only $0.3 \%$ immigrant children, rather than a school with the average percentage of $5.6 \%$.
} 
Table 6 Implied willingness to travel to schools with certain quality scores, ceteris paribus

\begin{tabular}{|c|c|c|c|c|}
\hline & (I) & (II) & (III) & (IV) \\
\hline Dependent variable & $\begin{array}{l}\text { School choice } \\
\text { within } 20 \mathrm{~km}\end{array}$ & $\begin{array}{r}\text { School choice } \\
\text { within } 20 \mathrm{~km}\end{array}$ & $\begin{array}{l}\text { School choice } \\
\text { within } 20 \mathrm{~km}\end{array}$ & $\begin{array}{r}\text { School choice } \\
\text { within } 20 \mathrm{~km}\end{array}$ \\
\hline Selection & $\begin{array}{l}\text { All first year } \\
\text { students }\end{array}$ & $\begin{array}{r}\text { Students in most } \\
\text { academic track } \\
(V W O)\end{array}$ & $\begin{array}{r}\text { Students in middle } \\
\text { academic track } \\
(\text { HAVO })\end{array}$ & $\begin{array}{r}\text { Students in lowest } \\
\text { general track } \\
(V M B O)\end{array}$ \\
\hline \multicolumn{5}{|c|}{ Willingness to travel in $\mathrm{km}$ to attend a school with a neutral quality score rather than a: } \\
\hline Most negative quality score & $\begin{array}{c}0.844^{*} \\
(0.323)\end{array}$ & N.A. & $\begin{array}{r}1.312 \\
(0.534)\end{array}$ & $\begin{array}{r}0.909 \\
(0.425)\end{array}$ \\
\hline Negative quality score & $\begin{array}{l}0.339^{\star *} \\
(0.119)\end{array}$ & $\begin{array}{r}0.013 \\
(0.121)\end{array}$ & $\begin{array}{c}0.167^{*} \\
(0.128)\end{array}$ & $\begin{array}{l}0.435^{\star *} \\
(0.182)\end{array}$ \\
\hline Positive quality score & $\begin{array}{r}-0.222^{\star * *} \\
(0.058)\end{array}$ & $\begin{array}{r}-0.314^{* *} \\
(0.098)\end{array}$ & $\begin{array}{r}-0.135^{\star} \\
(0.104)\end{array}$ & $\begin{array}{r}-0.132 \\
(0.136)\end{array}$ \\
\hline Most positive quality score & $\begin{array}{r}-0.209 \\
(0.218)\end{array}$ & $\begin{array}{r}-0.160 \\
(0.276)\end{array}$ & $\begin{array}{r}-0.420 \\
(0.885)\end{array}$ & $\begin{array}{r}-0.179 \\
(0.399)\end{array}$ \\
\hline \multicolumn{5}{|c|}{ - Standard errors of willingness to travel in parentheses, obtained though delta method. } \\
\hline
\end{tabular}

So far, one of our key findings is that the quality responses in school choice are mostly confined to the higher, more academic education tracks. This raises the question whether this is driven by differences in cognitive ability of (parents and) students - which determine each student's school track - or by differences in the socio-economic situation of households. In other papers on quality information and school choice (e.g. Hastings, Kane and Staiger, 2006) it is implied that higher socio-economic groups pay better attention to school quality information than other groups, thereby possibly enlarging inequities in the quality of education enjoyed. In order to check for the existence of differential quality responses in our sample, we therefore re-estimate the baseline conditional logit regressions with interactions terms of individual characteristics. These terms include all linear combinations of the three household characteristics income group, ethnicity and main income source with the distance variable and the quality scores. The estimated coefficients of the household interaction terms with a negative quality score (“-”) and with a positive 
quality score ("+") can be found in Table A in the appendix. Only two out of forty interaction coefficients are significantly different from zero. In contrast to the findings of Hastings et al. (2006), virtually no differences can thus be found in how important quality scores are for school choice of different socio-economic groups. Only in the regression for students in the lowest general track (Column VIII) income has the predicted impact. That is, children from higher income households in this track are more likely to choose a wellperforming school. We conclude that the way in which quality scores influence school choice thus differs by school track attended, which is driven by the student's ability and ambition, but not by the characteristics of the student's household.

Table 7 below presents three robustness checks for the individual level analysis which we discussed in Section 4.2. Column IX shows odds ratios for a conditional logit regression of school choice on the characteristics of all relevant schools within 10 , rather than 20 kilometers of each child's home address. The column was included to analyze the sensitivity of our school choice results to the chosen distance range. A smaller range apparently strengthens the estimated effects of the quality scores as the odds ratios are larger (smaller) and more significant than those in Column I. 


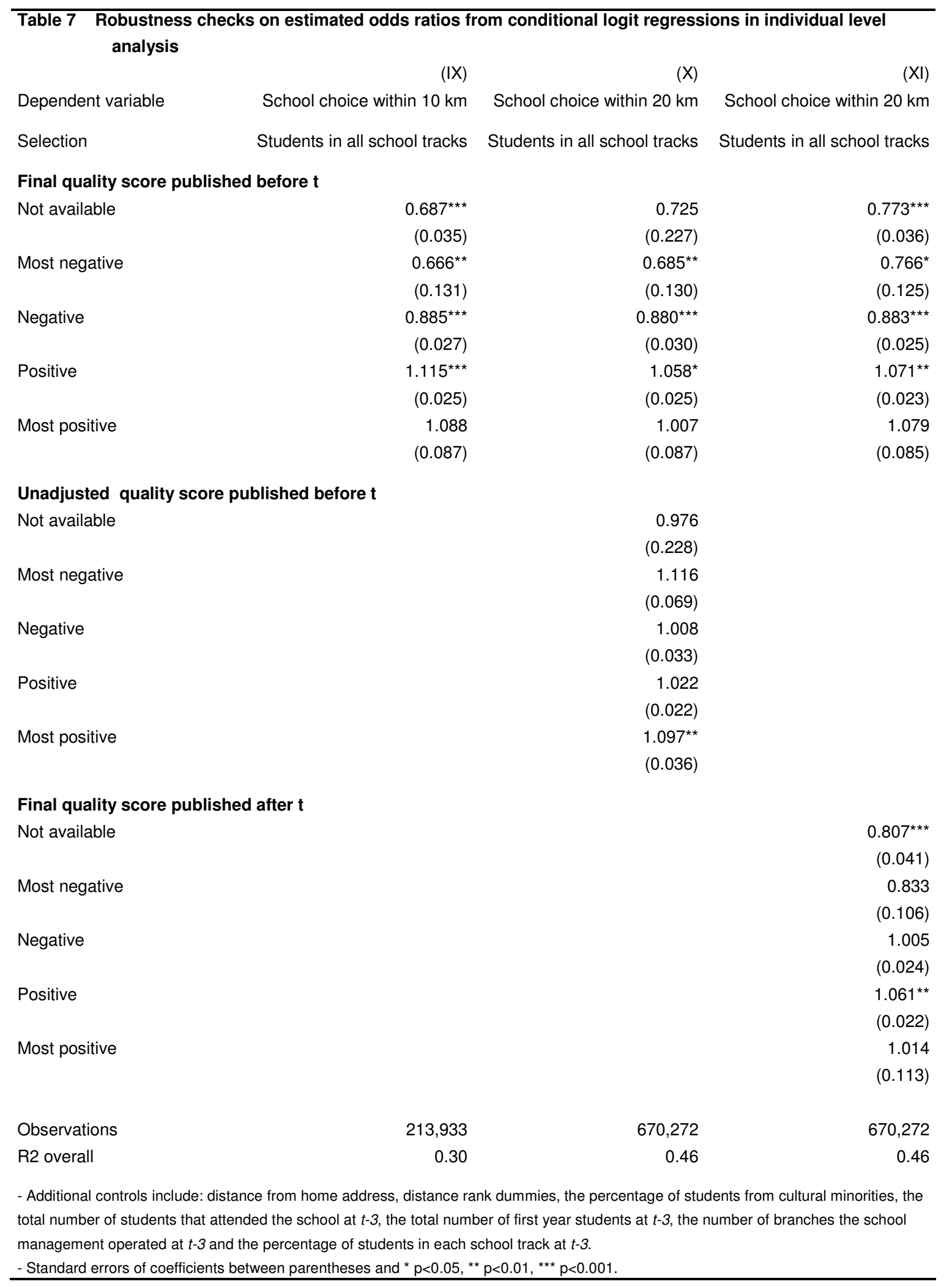


The estimates shown in columns $\mathrm{X}$ and $\mathrm{XI}$ are comparable to the robustness checks in the school level analysis (Columns VII and VIII in Table 4) in that they test for the additional effects of the unadjusted quality scores and of the final quality scores published at a later time. These variables are included to test whether the results found so far are troubled by confounding factors. As the association between unobserved factors such as the reputation of a school track and the unadjusted score is likely to be higher than for the adjusted score, the unadjusted score could potentially absorb the effects found for the final score. The results in Column $\mathrm{X}$ however show that this is generally not the case. The odds ratios for the final score are similar to those found in Column I and the odds ratios for the unadjusted score are insignificant, with the exception of the most positive score. Column XI finally demonstrates that the results for Trouw's final quality scores are robust to the inclusion of more recent information, that is, the quality score published at $t+1$. All in all, we conclude that also in individual choice behaviour the publicly available quality information plays a significant, albeit small, role. 


\begin{tabular}{|c|c|c|c|}
\hline & $(\mathrm{IX})$ & $(\mathrm{X})$ & $(\mathrm{XI})$ \\
\hline Dependent variable & School choice within $10 \mathrm{~km}$ & School choice within $20 \mathrm{~km}$ & School choice within $20 \mathrm{~km}$ \\
\hline Selection & Students in all school tracks & Students in all school tracks & Students in all school tracks \\
\hline \multicolumn{4}{|c|}{ Final quality score published before $t$} \\
\hline \multirow[t]{2}{*}{ Not available } & $0.687^{* * *}$ & 0.725 & $0.773^{\star * *}$ \\
\hline & $(0.035)$ & $(0.227)$ & $(0.036)$ \\
\hline \multirow[t]{2}{*}{ Most negative } & $0.666^{* *}$ & $0.685^{\star *}$ & $0.766^{*}$ \\
\hline & $(0.131)$ & $(0.130)$ & $(0.125)$ \\
\hline \multirow[t]{2}{*}{ Negative } & $0.885^{\star \star *}$ & $0.880^{* \star *}$ & $0.883^{* * *}$ \\
\hline & $(0.027)$ & $(0.030)$ & $(0.025)$ \\
\hline \multirow[t]{2}{*}{ Positive } & $1.115^{\star * *}$ & $1.058^{*}$ & $1.071^{* *}$ \\
\hline & $(0.025)$ & $(0.025)$ & $(0.023)$ \\
\hline \multirow[t]{2}{*}{ Most positive } & 1.088 & 1.007 & 1.079 \\
\hline & $(0.087)$ & $(0.087)$ & $(0.085)$ \\
\hline
\end{tabular}

Unadjusted quality score published before $\mathbf{t}$

Not available

1.116

(0.069)

1.008

(0.033)

1.022

(0.022)

$1.097^{* *}$

(0.036)

Most positive

Final quality score published after $\mathbf{t}$

Not available

$0.807^{\star \star \star}$

$(0.041)$

0.833

Most negative

(0.106)

Negative

1.005

(0.024)

Positive

Most positive

Observations

213,933

670,272

670,272

R2 overall

0.30

0.46

0.46

- Additional controls include: distance from home address, distance rank dummies, the percentage of students from cultural minorities, the total number of students that attended the school at $t-3$, the total number of first year students at $t-3$, the number of branches the school management operated at $t-3$ and the percentage of students in each school track at $t-3$.

- Standard errors of coefficients between parentheses and ${ }^{*} p<0.05,{ }^{* *} p<0.01,{ }^{* * \star} p<0.001$ 


\subsection{Discussion}

In this subsection, we discuss the similarities and differences between the school level analysis and the individual level analysis in the Trouw quality response estimates. Table 8 summarizes the baseline results found for both strata, in terms of the additional number of students that enroll at a particular school track in the year after the Trouw publication. The school level fixed estimates in the first column are directly copied from Column (I) in Table 3. Column (II) depicts additional results from a similar regression that is estimated using OLS rather than fixed effects. The individual level estimates shown in the third column are calculated using the odds ratios from Column (I) in Table 5 and the average number of students per quality score category from Table 1 .

Table 8 demonstrates that in both strata we have found significant effects in the expected direction of publicly available school quality scores. Individual students and their parents respond to quality information and schools notice the net effect of these responses in the number of new first year students they receive. In this sense, the estimates of the school level analysis and the individual level analysis reinforce each other. However, we also observe two differences. First, the size of the effects is larger when analyzing the individual data and when using the school level data to estimate OLS results. Second, in the school track fixed analysis significant effects on student inflow are confined only to schools that perform most positively (“++”).

Obviously, some of the dissimilarities between the individual and school-level effects stem from the different time spans covered in the two datasets. The school level analysis uses school track information from 1996-2003 (published in 1998-2005) while in the individual analysis we focus on students entering secondary education in 2003. Individual estimates may also differ from the results in column (I), because we are better able to control for confounding factors using a fixed effects methodology. This notion is 
confirmed by inspecting the OLS estimates for the school level data. As these are very close to the individual level estimates, this suggests that confounding factors, in particular reputation, indeed generate most of the differences between the individual and school level results. As schools with a good reputation often perform well quality wise, reputation determines part of our estimates of the Trouw scores in the individual analysis. Stated differently, in the individual analysis the Trouw score estimates may be interpreted as proxies for the overall reputation effect on school choice, rather than as the isolated impact of the Trouw publication.

Omitted variables that are negatively correlated with the Trouw scores produce an underestimation of the effect of scoring most positively (“++”) in the individual and OLS analysis. This is due to the procedure Trouw uses to correct its final scores for the initial quality of students. As explained in Section 2, the most important control variable is the percentage of students from cultural minorities. Schools that have many of these students are believed to be at a disadvantage, such that their final scores are upgraded to a certain degree. The average percentage of immigrant children is thus relatively high in the group of school tracks that performs most positively (“++”). One could imagine some omitted variables that make a secondary school less attractive to be positively associated with this high percentage (like a negative reputation or low quality facilities). These confounding factors could then lead to an underestimation of the "++"-score effect in the individual analysis, whereas they are controlled for in the school fixed effects analysis.

Table $8 \quad$ Comparison fixed effects school level results and conditional logit individual level results

\begin{tabular}{lrrr} 
& (I) & (II) & (III) \\
Response in number of students & School level data & School level data & Individual level data \\
Estimation method & Fixed effects & OLS & Conditional logit \\
Final quality score published after t & & & \\
Most negative & -2.279 & $-16.941^{* * *}$ & $-15.834^{* *}$ \\
Negative & $-1.885^{\star * *}$ & $-7.436^{* * *}$ & $-8.760^{* \star *}$ \\
Positive & $1.207^{*}$ & $3.762^{* *}$ & $7.128^{* \star *}$ \\
Most positive & $7.729^{*}$ & 3.962 & 5.658 \\
\hline
\end{tabular}




\section{Conclusions}

In this paper, we examine school choice responsiveness to information on high school quality published by a national newspaper ('Trouw'). So far, the literature on school quality information has focused on government accountability programs targeted at lowperforming schools and on countries where either school catchment areas exist, or where there is substantial heterogeneity in school fees. We contribute to the literature by analyzing a private initiative to disclose quality information that covers the entire quality distribution of schools in a country with free school choice and negligible school fees. Moreover, we argue that we identify a causal effect of the quality information on school choice, due to a substantial lag between the registration of quality information and its publication.

Our analysis uses both a longitudinal school level dataset and an individual level dataset of secondary school students with detailed information at the level of students' households. First, we study the causal effect of quality scores on the influx of new high school students in the panel dataset of schools. School (track) fixed effect regressions are estimated of the number of new first year students at each school on the quality scores published by Trouw during the previous year. We find that students and parents do pay attention to the quality information. Negative (positive) school quality scores decrease (increase) the number of students choosing a school in the year after publication. The size of these effects is typically small, except for the effect of receiving the most positive score (“++”) for academic school tracks (' $V W O$ '). The inflow of first year students at an academic school track goes up by 16 to 18 students after the track has received this quality score.

Second, we study individual school choice behavior to address the relative importance of the quality scores and the potential differences in the quality response 
between socio-economic groups. For this purpose, we run conditional logit regressions of school choice on the set of all relevant school tracks within $20 \mathrm{~km}$ of the child's home address. Besides Trouw's quality scores, the independent variables in these regressions include distance from home, distance rank order of the school, number of students and other school track characteristics. Although we find the probability of attending a school to be affected by its quality score, this probability is mainly driven by the traveling distance. Students are willing to travel an estimated 222 meters more in order to attend a wellperforming rather than an average scoring school.

Like in the school level analysis, students who attend an academic school track show the highest inclination to attend a well-performing school. This difference in quality response could be either driven by differences in cognitive ability - which determine each student's school track — or by socio-economic differences. In regressions that include interaction terms of the quality scores with several household characteristics, we cannot find significant differences in quality response between specific socio-economic groups. This indicates that the Trouw score response is larger for students that attend the most academic school track because of differences in cognitive ability and ambition. 


\section{References}

Bishop, John H. (1998). "Privatizing Education: Lessons from Canada and Europe.” CAHRS Working Paper 98-21.

Downes, Thomas, A., and Jeffrey E. Zabel (2002). "The impact of school characteristics on house prices: Chicago 1987-1991." Journal of Urban Economics, 52, 1-25.

Dijkstra, Anne B., Jaap Dronkers, and Sjoerd Karsten (2004). "Private Schools as Public Provision of Education: School Choice and Market Forces in the Netherlands" in : Patrick J. Wolf, and Stephen Macedo (eds): Educating Citizens. International Perspectives on Civic Values and School Choice, Washington DC: Brookings Institute Press.

Dijkstra, Anne B., Sjoerd Karsten, René Veenstra, and Adrie J. Visscher (2001). Het Oog der Natie: Scholen op Rapport. Standaarden voor de Publicatie van Schoolprestaties, Koninklijke van Gorcum, Assen.

Dronkers, Jaap (1999). "Veranderden Leerlingaantallen in het Voortgezet Onderwijs in het Schooljaar 1998-1999 door de Publicatie van Inspectiegegevens en de Berekening van het Schoolcijfer door Trouw in Oktober 1997?" Tijdschrift voor Onderwijsresearch, 24, 63-66.

Figlio, David N, and Maurice E. Lucas (2004). "What's in a Grade? School Report Cards and the Housing Market” The American Economic Review, 94, 591-604.

Hastings, Justine S., Thomas J. Kane, and Douglas O. Staiger (2005). "Parental Preferences and School Competition: Evidence from a Public School Choice Program”. NBER Working Paper 11805 .

Hastings, Justine S., Richard van Weelden, and Jeffrey Weinstein (2007). "Preferences, Information, and Parental Choice Behavior in Public School Choice". NBER Working Paper 12995.

Hastings, Justine S., and Jeffrey Weinstein (2008). "Information, School Choice and Academic Achievement: Evidence from Two Experiments" The Quarterly Journal of Economics, 123, 1373-1414.

Kane, Thomas J., Stephanie K. Riegg, and Douglas O. Staiger (2006). "School Quality, Neighborhoods, and Housing Prices" American Law and Economics Review, 8, 183-212.

Koning, Pierre, and Karen van der Wiel (2010). "School Responsiveness to Quality Rankings: An Empirical Analysis of Secondary Education in The Netherlands" CPB Discussion Paper 149.

Kling, Jeffrey R., Sendhil Mullanaithan, Eldar Shafir, Lee Vermeulen, and Marian V. Wrobel (2008). "Misperception in Choosing Medicare Drug Plans", manuscript Harvard University

Pope, Devin G. (2009). "Reacting to Rankings: Evidence from 'America's Best Hospitals"” Journal of Health Economics, 28, 1154-1165. 


\section{Appendix}

Figure A Excerpt from Trouw school quality publication in 2005

Trouw woensdag 14 december 2005

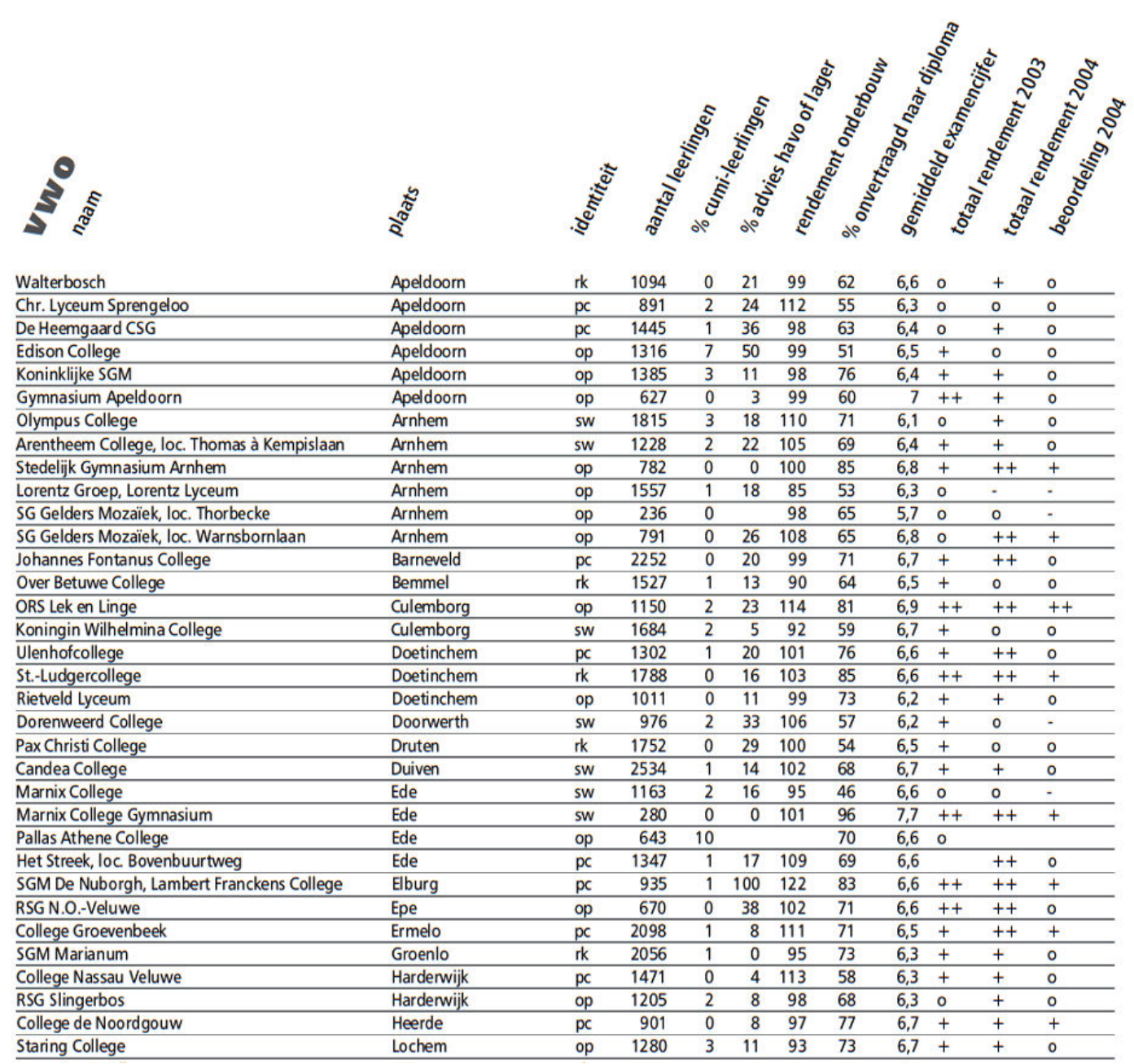


Figure B Time line publication of public quality information

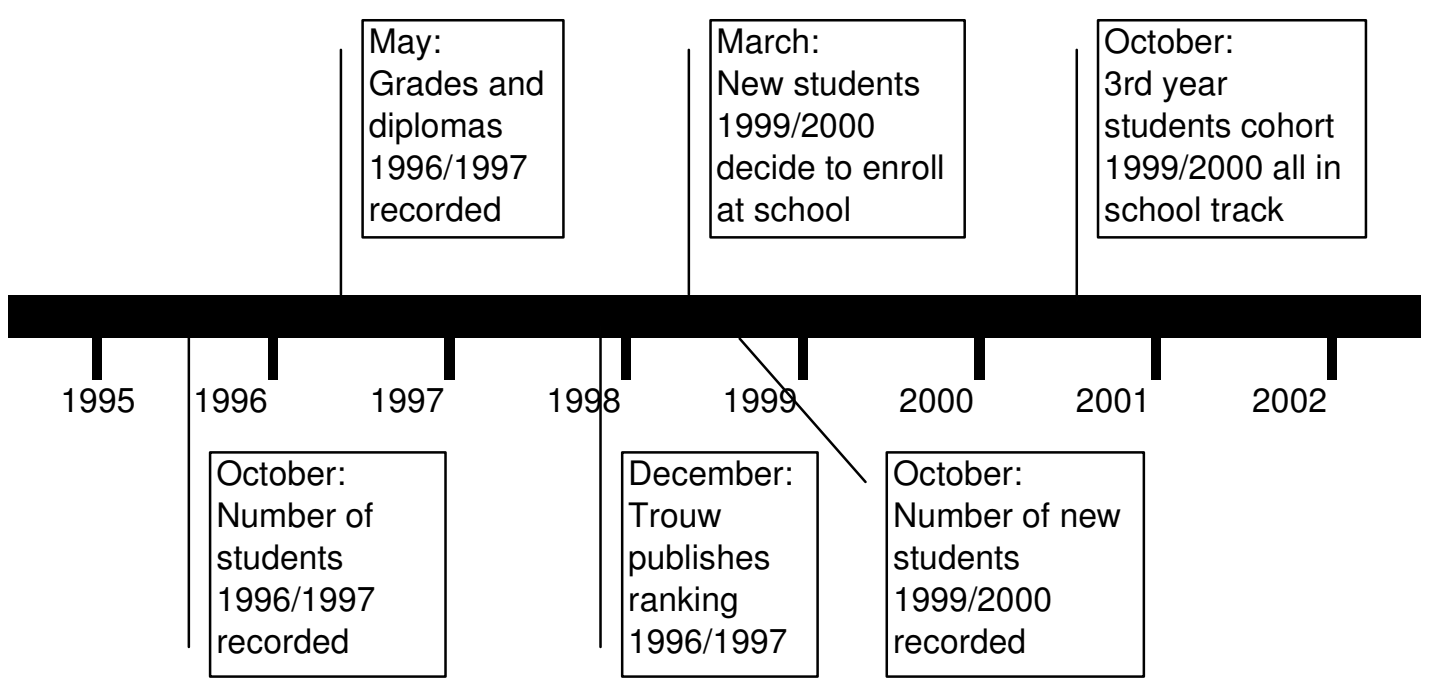




\begin{tabular}{|c|c|c|c|c|}
\hline & $(\mathrm{V})$ & $(\mathrm{VI})$ & (VII) & (VIII) \\
\hline Dependent variable & $\begin{array}{r}\text { School choice } \\
\text { within } 20 \mathrm{~km}\end{array}$ & $\begin{array}{l}\text { School choice } \\
\text { within } 20 \mathrm{~km}\end{array}$ & $\begin{array}{l}\text { School choice } \\
\text { within } 20 \mathrm{~km}\end{array}$ & $\begin{array}{r}\text { School choice } \\
\text { within } 20 \mathrm{~km}\end{array}$ \\
\hline Selection & $\begin{array}{l}\text { All first year } \\
\text { students }\end{array}$ & $\begin{array}{r}\text { Students in most } \\
\text { academic track } \\
(V W O)\end{array}$ & $\begin{array}{r}\text { Students in middle } \\
\text { academic track } \\
(\text { HAVO })\end{array}$ & $\begin{array}{r}\text { Students in lowest } \\
\text { general track } \\
(\mathrm{VMBO}-g t)\end{array}$ \\
\hline \multicolumn{5}{|c|}{ Interactions with negative quality score (“"-”) } \\
\hline Low income household & Referen & & & \\
\hline \multirow[t]{2}{*}{ Middle income household } & 0.059 & -0.122 & -0.039 & 0.187 \\
\hline & $(0.07)$ & $(0.15)$ & $(0.12)$ & $(0.11)$ \\
\hline \multirow[t]{2}{*}{ High income household } & -0.012 & -0.278 & -0.154 & 0.218 \\
\hline & $(0.08)$ & $(0.15)$ & $(0.13)$ & $(0.12)$ \\
\hline Native Dutch household & Referen & & & \\
\hline \multirow[t]{2}{*}{ Immigrant household } & 0.082 & 0.145 & 0.174 & -0.008 \\
\hline & $(0.06)$ & $(0.13)$ & $(0.11)$ & $(0.10)$ \\
\hline Wage receiving & Referen & & & \\
\hline \multirow[t]{2}{*}{ Entrepreneurial household } & -0.010 & -0.154 & -0.057 & 0.102 \\
\hline & $(0.06)$ & $(0.11)$ & $(0.11)$ & $(0.10)$ \\
\hline \multirow[t]{2}{*}{ Benefit receiving household } & -0.121 & -0.217 & -0.127 & -0.014 \\
\hline & $(0.12)$ & $(0.30)$ & $(0.22)$ & $(0.16)$ \\
\hline \multicolumn{5}{|c|}{ Interactions with positive quality score ("+") } \\
\hline Low income household & Referen & & & \\
\hline \multirow[t]{2}{*}{ Middle income household } & 0.102 & -0.103 & 0.108 & $0.219^{*}$ \\
\hline & $(0.06)$ & $(0.16)$ & $(0.12)$ & $(0.10)$ \\
\hline \multirow[t]{2}{*}{ High income household } & 0.053 & -0.201 & -0.053 & $0.297^{* *}$ \\
\hline & $(0.07)$ & $(0.16)$ & $(0.12)$ & $(0.12)$ \\
\hline Native Dutch household & Referen & & & \\
\hline \multirow[t]{2}{*}{ Immigrant household } & -0.054 & -0.160 & -0.174 & 0.116 \\
\hline & $(0.06)$ & $(0.11)$ & $(0.11)$ & $(0.10)$ \\
\hline Wage receiving & Referer & & & \\
\hline \multirow[t]{2}{*}{ Entrepreneurial household } & -0.020 & 0.015 & -0.101 & -0.010 \\
\hline & $(0.05)$ & $(0.09)$ & $(0.10)$ & $(0.09)$ \\
\hline \multirow[t]{2}{*}{ Benefit receiving household } & 0.076 & -0.231 & 0.031 & 0.174 \\
\hline & $(0.12)$ & $(0.26)$ & $(0.23)$ & $(0.16)$ \\
\hline \multirow{2}{*}{$\begin{array}{l}\text { Observations } \\
\text { R2 overall }\end{array}$} & 670,272 & 194,834 & 184,655 & 290,783 \\
\hline & 0.46 & 0.46 & 0.47 & 0.46 \\
\hline \multicolumn{5}{|c|}{$\begin{array}{l}\text { - Additional controls include: Trouw quality scores, distance from home address, interactions with distance and the above characteristics, } \\
\text { distance rank dummies, the percentage of students from cultural minorities, the total number of students that attended the school at } t-3 \text {, } \\
\text { the total number of first year students at } t-3 \text {, the number of branches the school management operated at } t-3 \text { and the percentage of } \\
\text { students in each school track at } t-3 \text {. } \\
\text { - Standard errors between parentheses. } \\
\text { - }{ }^{*} p<0.05,{ }^{* \star} p<0.01,{ }^{* * \star} p<0.001\end{array}$} \\
\hline
\end{tabular}

